\title{
When does the Paramedics' Duty End?
}

Hasan Erbay*

Faculty of Medicine, Department of History of Medicine and Ethics, Afyon Kocatepe University, Turkey

*Corresponding author: Hasan Erbay, Faculty of Medicine, Department of History of Medicine and Ethics, Afyon Kocatepe University, Turkey, Tel: +90 505 3963828; Email: hasaberbay@yahoo.com

Received date: June 27, 2016; Accepted date: July 16, 2016; Published date: July 18, 2016

Copyright: ( 2016 Erbay H. This is an open-access article distributed under the terms of the Creative Commons Attribution License, which permits unrestricted use, distribution, and reproduction in any medium, provided the original author and source are credited

\section{A Case}

A seventy-five years old woman is suffering from ischemic (or) cerebrovascular attack in an ambulance on the way to the hospital. The ambulance is a governmental one and there is no need for health insurance for the patient. Daughter of the patient is in the ambulance and reading a Holy Book in the immediate vicinity. While the patient is getting worse, prehospital emergency care givers start the endotracheal intubation procedure. However, the daughter opposes this intervention strongly and says: "Why do not you let her die in a peace and also listen sacred words at her last chance?!"

\section{Question}

The crucial question is "When does the paramedics' duty end?"

\section{Implifications}

First of all, it needs to accept that there are wide range of issues related to prehospital emergency medicine and refusal of treatment.

For defining it clearly, it may be categorized in four duties for paramedics in this situation. It can also be called ethical, legal and social implifications (ELSI) of prehospital emergency care. However, clinical issues probably, take much more important role of the process.

When general principles surrounding consent and refusal can be discussed in theory, it is often more complicated in the real settings [1]. Besides, it is very difficult to consider in advance every possible conflict that might arise. With a view to emergency care for patients, the emergency care givers have an intrinsic duty to understand not only clinical but also ELSI of the case. The answers are not so clear in many times and the conditions are slippery slope, at all. Besides, it might be likely resulted in unintended consequences.

Four duties for paramedics in this case are:

\section{1- Clinical Duty}

There are global aspects for clinical duties all over the world. In emergency situations, health care providers are accepted as that is their duty to evaluate the patient. Especially in professional environment (in an ambulance here), expectation of the society from health care professionals that provide emergency care in a paternalistic approach and perform an act of benevolence [2].

As a requirement of professionalism, paramedics should perform emergency care to the patient that what kind of care she needs. Paramedics have the medical equipments in the ambulance to consider the situation for the patient and should they determine the severity of the clinical status. Most of the clinical signs and measurements are clear for determining the emergency, and there are optimized algorithms for what to do in every clinic situations.
Basically, there are not so much choices in clinical aspects for paramedics in an emergency acting in beneficence of the patient. The duty is clear; follow the clinical signs.

\section{2- Ethical Duty}

Refusal of treatment is one of the fundamental rights of the patients [3]. All patients have both a right to treatment and also a right to refuse treatment. However, it raises dilemma in an emergency. Giving emergency care is considered as a humanitarian duty [4]. Furthermore, prehospital emergency health professionals tended to adopt a more paternalistic approach [5].

The most critical conflict occurs at the scene that the paramedic faces difficulties in decision-making. Issues about consent and refuse the treatment are to be considered together as they are closely related to each other [1]. For the refusal to be valid, first requirement is the patient's capacity to make any decision. If it does not meet, there is no need to other processes of informed consent [6]. Then, paramedics should try to do their best for unconscious patient. Intubating the patient and performing the procedure is an ethically sound solution for that case.

But, the interesting thing makes the situation as a slippery slope is cultural diversity. In some culture, it is expected from health care providers to act paternalistic for the patients, and in some culture act respectively to individual decision of the patients. Cultural diversity surely makes the world better place, however it is also an obstacle to reach global ethics idea of some bioethical issues like refuse of treatment. It is about the role of the people that who would decide on the patient's best interest and values. Is that person someone relative of the patient, or professional emergency care givers?

\section{3- Legal Duty}

The legal concepts for prehospital emergency care, refusal of treatment, right to die in peace and relatives / bystanders in ambulance, vary country to country. It depends on the legal aspects of the community and it is clearly very difficult to make a global discussion on this issue, at all.

Fortunately, one of the things that gets the conflicts simple is effective communication [7,8]. About the communication skills; "Making good ethical decisions requires a trained sensitivity to the 'human factor' of patient interaction. It is necessary to have a welldeveloped awareness of how alternative actions should be valued as 'good' and 'bad', 'right' and 'wrong"' says, Nordby [9].

\section{4- Social Duty}

Some issues related to religion, dying, end-of-life care and etc. are understandably changeable on society's view. It is highly important for 
paramedics maybe not to believe exactly as the communities have, however know and respect the social values of the current community he works in. For example in Thailand; hospitals and related health services (i.e., ambulances) as places to die, they are amoral, dangerous, devoid of ceremonial history and haunted by spirits [10]. People would like to prefer to die at home because of moral power from a history of beneficial ceremony.

Additionally, it is very common and desirable thing in many societies that reading and listening some kind of religious words and praying for the dying one, when someone from the family is in quotes. It is also an issue of human dignity that emergency care providers should take an account. It is essential as an ethico-social point to recognize the humanity and individuality of every patient to preserve and promote human dignity in diverse cross-cultural settings [11]. Surely, respect the patient as a unique human being, thus promoting patient dignity [12]. People know the relatives on how the patient would like to die. It is not only health care providers to decide what to do about dying patient, but also relatives who knows the patient's values and end-of-life desires.

As professional values; telling the truth, telling bad news, humanity, compassion to patient and her relatives and communication skills are big issues in prehospital emergency care. It might be the great indicator of professionalism for a paramedic that sometimes there is medically nothing to do for the patient, however choosing the right words for telling the situation make a significant difference to comfort the relatives. Communication skills of the health care givers are closely related to internalize the community's values, at all.

\section{Discussion}

It is the fact that some experts tend to consider legal issues in the forefront on these issues more than other implifications of the cases [13]. Of course, this behavior is partly understandable as nobody wants to get into trouble with the law. However, the legality is not all everything in current times. For example, slavery was legal once upon a time but it was not ethical. So, it does not mean that if something is legal, it is also acceptable for ethical aspects.

Another opposition to consider ELSI of (prehospital emergency, here) medical care is, the possible difficulties in definition of the duty on any profession. In today's society, it follows a trend that of all professions should divide into unique branches that specifying only restricted part of the whole. Unfortunately, it is concluded many people knowing the some special issue but not the whole. In modern times, it needs the conceptual professionals in all parts of the professions [14].

One of the important things on conceptual professionalism is education process of the profession. What makes the paramedic selfconfident is the education and his knowledge on all aspects of his duties. When he knows there is nothing better to do than he did, he may get satisfaction of the job. Provided that a well-equipped training and practical education, most of the professionals would find the better way of their duties and the society would benefit it, as well.

At the end, there is probably one point that leading a doubt is malfeasance within the scientific and clinical community. This situation is, of course not only specific for prehospital emergency medicine but all medicine including health-care professionals-patient relationship. It needs awareness of malfeasance for health-care community and institutional self-control mechanisms.

\section{Answer}

It depends on which implifications the paramedics mostly take into account. It will be probably better to consider ELSI and clinical assessment all together. However, it is very difficult attempt to accommodate with solutions and analysis in advance on emergency cases. All cases are unique and therefore it needs to think on the issues in advance.

The important thing is to be aware of all aspects of the case, try to the better, learn ELSI of the profession, try to improve communication skills and get calm.

And the last voice from the transceiver is: "Paramedic, your duty never ends!"

\section{References}

1. Geiderman JM (2001) Ethics seminars: Consent and refusal in an urban american emergency department: Two case studies. Acad Emerg Med 8: 278-281.

2. Erbay H (2014) What if the patient says "No!" in the ambulance: An ethical perspective for assessment of capacity in the prehospital emergency setting. El Mednifico J 4: 2-4.

3. (1994) A declaration on the promotion of patient' rights in Europe. WHO $1-15$.

4. (2006) WMA International Code of Medical Ethics. World Medical Association (WMA) pp: 1-2.

5. Erbay H, Alan S, Kadioglu S (2013) Attitudes of prehospital emergency care professionals toward refusal of treatment: A regional survey in Turkey. Nurs Ethics 21: 530-539.

6. Erbay H, Alan S, Kadıoglu S (2010) A case study from the perspective of medical ethics: refusal of treatment in an ambulance. J Med Ethics 36: 652-655.

7. Nordby H (2013) Should paramedics ever accept patients' refusal of treatment or further assessment? BMC Med Ethics 14: 44.

8. Włoszczak-Szubzda A, Jarosz MJ, Goniewicz M (2013) Professional communication competences of paramedics--practical and educational perspectives. Ann Agric Environ Med 20: 366-372.

9. Nordby H (2013) Ethics in prehospital emergency medicine: An ethical dilemma in patient communication. Webmedcentral Med Ethics pp. 1-5.

10. Stonington SD (2012) On ethical locations: The good death in Thailand, where ethics sit in places. Soc Sci Med 75: 836-844.

11. Cheraghi MA, Manookian A, Nasrabadi AN (2014) Human dignity in religion-embedded cross-cultural nursing. Nurs Ethics 21:916-928.

12. Abelsson A, Lindwall L (2015) What is dignity in prehospital emergency care? Nurs Ethics 23: 1.

13. Walker AF (2002) The legal duty of physicians and hospitals to provide emergency care. CMAJ 166: 465-469.

14. Aliakbari F, Hammad K (2014) Ethical and legal challenges associated with disaster nursing. Nurs Ethics 22: 493-503. 